\title{
Analysis on Foreign Exchange Intervention in the International Financial Market
}

\author{
Wenyou Gao ${ }^{1} \& \mathrm{Jie}_{\mathrm{Zhao}}^{2}$ \\ ${ }^{1}$ School of Economics and Management, Changchun University of Science and Technology, Changchun, China \\ ${ }^{2}$ School of Economics and Management, China University of Petroleum (East China), Qingdao, China \\ Correspondence: Wenyou Gao, School of Economics and Management, Changchun University of Science and \\ Technology, Changchun 130022, Jilin, China. E-mail: gaowenyoujp@126.com
}

Received: October 14, 2014

Accepted: October 27, 2014

Online Published: November 12, 2014

doi:10.5430/jms.v5n4p117

URL: http://dx.doi.org/10.5430/jms.v5n4p117

\begin{abstract}
Based on the relations of Exchange Rate to one Nation's Macroeconomics, the paper concretely analyzed the Path and Model of FX intervention in the International Financial Markets. The author hope the paper will help China to find a way in which the reasonable intervening scheme relative to the exchange rate between RMB and a basket of foreign currencies can be established, thus changing China's future economic development for the better.
\end{abstract}

Keywords: full employment, BP minus effective line, unemployment rate

\section{Introduction}

The so-called Foreign Exchange (FX) Intervention is: the country's Monetary Authorities, as an intervening group, would buy (or sell) a certain scale of specified foreign currency, at the same time, selling (or buying) equivalent local currency in the Foreign Exchange market (mainly in the form of OTC FX Margin Trading market), by means of virtual (or real) trading method, which changes supply and demand of targeted foreign currency and local currency, then adjusting the price of the two; the main purpose of the government is - in a certain period of time, to create the new Nominal Effective Exchange Rate between the target and local currency, therefore making franchise reactions for local currency in terms of a basket of foreign ones.

Intervention is an important part of a country's Exchange Rate Policy. When the country's currency were to be Internationalized and traded in the form of virtual transactions among the International Financial markets, the intervening approach and methods would become very complicated. In view of this situation, we need the deep study on the related nation's policies so as to learn the experience for our country's Currency Intervention Mechanism, thus providing a good reference for the future.

\section{An Overview to Problems between the Exchange Rate and One}

\subsection{Country's Macroeconomics}

The Exchange Rate is the price of one currency in terms of another. And relevant Foreign Exchange (FX) policy is an important part of a country's financial system, meanwhile influencing the country's macroeconomic stability. Starting from the view of macro-economy, for an open economy, countries should adopt appropriate macroeconomic policies to improve the employment of local residents as far as possible, finally making two economy class (Production and Consumption) in a balanced level.

Figure 1 shows a process of implementing a country's macroeconomic policy in detail. As shown: if a country's real Gross National Product (GNP, the Output) Y1 were to be greater than the initial ideal GNP (Yf - " $\mathrm{f}$ " means Full Employment), the country would need to expand monetary policy and loosen fiscal policy (such as tax lowering and monetary easing, etc.), namely moving the IS curve and LM curve to the right, thus making LM' curve, IS' curve and $\mathrm{Y} 1$ in the first quadrant intersect to $\mathrm{O}^{\prime}$ point, therefore producing a positive effect; then lowering Interest Rates at the same time, therefore making $\mathrm{O}$ 'point and $\mathrm{R}$ axis (interest rate) intersect to R2; for $\mathrm{E}$ axis, intervening the FX market, depreciating local currency, pushing nominal exchange rate E1 (directly quoted) to E 2 point. In the second quadrant, there is a BP line, mainly reflecting the correlation between interest rate and exchange rate. By the aforesaid manners, Point $\mathrm{H} 1$ would be adjusted to H2, corresponding to R 2 . 
Through the implementation of the policies, the country's production and consumption will reach to a new equilibrium, meanwhile, expanding domestic demand, promoting the export, finally improving the national employment situation.

If further analysis was carried out on the Figure 1, we can find that: the first quadrant may seem complicated, but decisions could be made within the border of one country; however, in the second quadrant, the effect must depend on the international financial market - from a deeper sense, the price of domestic and foreign currencies is not only decided by the will of the relative government, but also experiencing the trials of political, diplomatic, military and other games among international economies, so its process is very complex. Again as shown in Figure 1, we assume that $\mathrm{E}$ axis can not change as per our expectation in the second quadrant, namely: the E1 point unchanged, then intersecting R2 point to $\mathrm{H} 3$, moving BP line rightward to $\mathrm{H} 3$ points, there will appear to be a new "BP - line" (BP Minus Effective Line). At the second quadrant, moving right means "negative", so we call it as negative effects of exchange rate policy. And the negative effects will reverse the positive effect of the first quadrant. The result is: in domestic market, due to loose monetary and fiscal policy, inflation would appear to be true; however, as appreciation of domestic currency in terms of foreign ones, the country's export would be restrained, the national employment cannot be fully improved; when the changing rate of inflation becomes faster than that of domestic currency depreciation, such kind of devaluation will be more harm than good.

So it is clear that: all developed or less developed economies always directly or indirectly make adjustments to the exchange rate between domestic and foreign currencies for their own benefits. In the course of East Asian Financial Crisis, ASEAN, Japan, South Korea and other countries or economies adopted currency devaluation policies, which are called "Beggar Thy Neighbors"; as well, The global financial crisis taking place in 2008, the currencies in developed countries, such as the U.S. dollar, the Euro, the Sterling Pound, the Australian dollar and so on, depreciated in a large scale (except Japanese Yen) — that is to say: for a country's macro- economy, Exchange Rate Adjustment can not be avoided! So, how to intervene a country's exchange rate level in the international financial markets should be taken into our consideration.

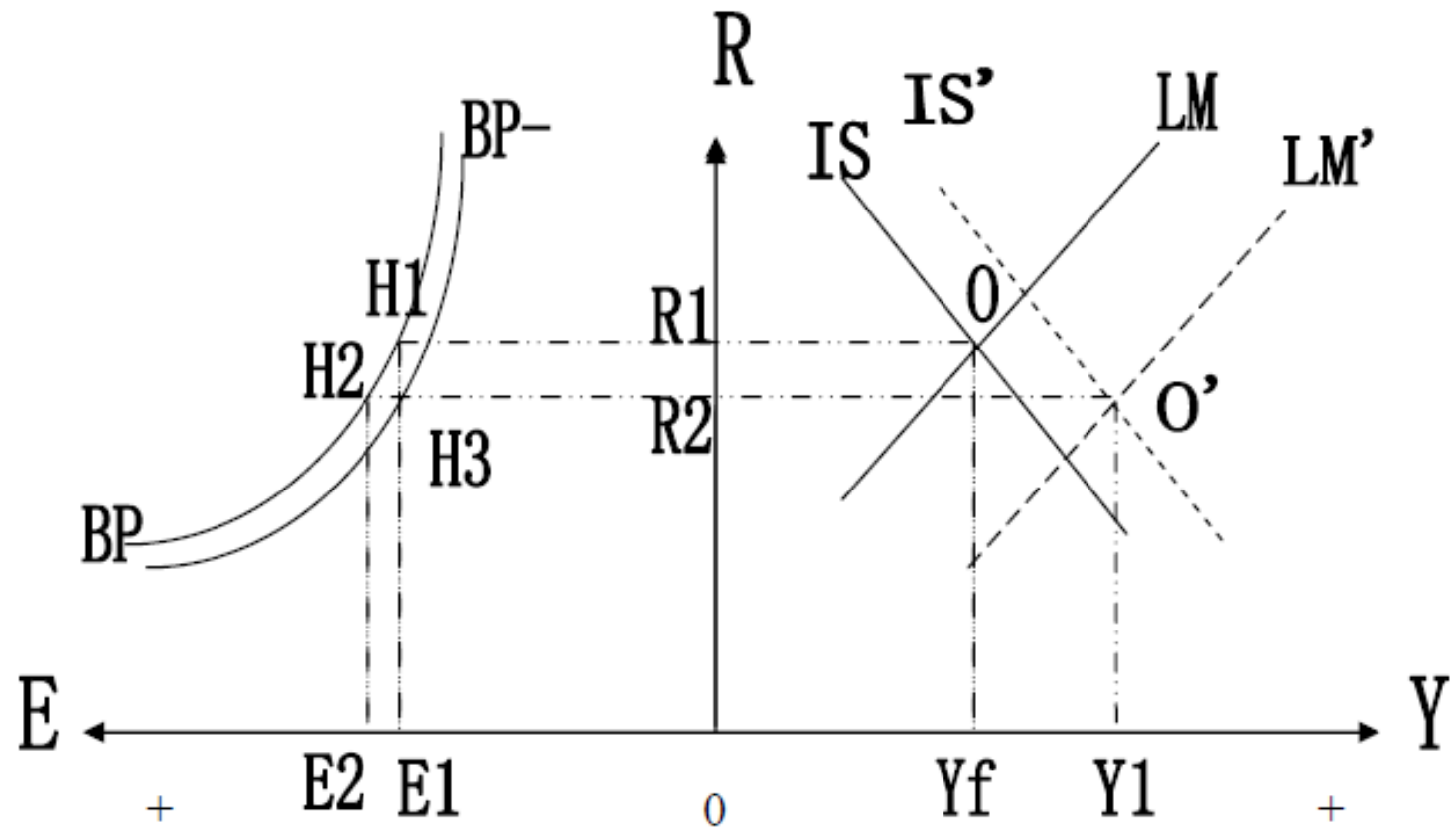

Figure 1. IS and LM Curve Model in terms of macro economic effect

Resource: Paul R. Krugman, Maurice Obstfeld, International Economics (Theroy and Policy), Fifth Edition, 2000, P477-478.

\section{FX Intervention Model Analysis}

\subsection{Trajectory Analysis on the Movement of Exchange Rate}

The price $\mathbf{E}$ of a pair of currencies adopts a random fluctuation in different time series, perfectly in line with the 
"Geometric Brownian Motion" pattern—while, lnE approximately complying with "Standard Normal Distribution". And in a certain range, the exchange rate fluctuation's curve has one or several peaks, which can be seen as "resistance points"; At the same time, the curve within the band also has one or several troughs, called as a "support points". Formation of resistance and support level is caused by the investors' expectations; and investors' psychologies are influenced by the international political, economic, military and other factors, but also by the manipulation form big hands "oligarchs".

So, the pattern that traders expect is: if the exchange rate were to go down, we would find support point according to former bottoms, if all the front bottoms penetrated, with the concept of "normal distribution", we could find a "new" support level as per proportion of the identified level (e.g., 0.618); On the other hand, we could find out resistance point as per former tops in the range, if the top broken, to the same concept, we would determine the proportion (1.618) to expect "new" top of the range. By this kind of cycle, the mindset is to a large extent that affects exchange rate movements.

At the same time, responding to uncertainty from currency fluctuations caused by asymmetric information system, currency traders would enter financial markets at a certain price in long-position or short-position form after admission, setting 100-150 points of "Stop Loss" in the opposite direction, which would limit risk within a certain range.

\subsection{Analysis on the Path to Intervening FX Markets}

Now that we have understood the trajectory of underlying assets (Exchange Rate), so the essence of the intervention paths is: in the foreign exchange market, if the exchange rate were to bias towards the tendency that might do harm to domestic economy, the Intervention Authority would make relevant $E$ volatility curve appear to change adversely, namely creating a turning point thereof, finally hedging the expectation of the markets.

We use B ( $t$ ) represents the buying numbers of a pair of currencies related to Time $T$ function; $S(t)$ for sale quantity relative to the function of time $\mathrm{T}$; where,

$\mathrm{E} \uparrow=f(\mathrm{~B} \uparrow, \mathrm{S} \downarrow)-$ under the direct quotation: $\mathrm{S}$ constant, $\mathrm{E}$ rise with the increase of $\mathrm{B}$, which means devaluation of local currency; On the contrary, meaning domestic currency's appreciation. The first-order and second -order derivative of $\mathrm{E}$ related to $\mathrm{T}$ is:

$$
\begin{gathered}
\frac{d E}{d t}=\left(\frac{\partial f}{\partial B} \times \frac{d B}{d t}\right)+\left(\frac{\partial f}{\partial S} \times \frac{d S}{d t}\right) \\
\frac{d^{2} E}{d t^{2}}=\frac{d\left(\frac{\partial f}{\partial B} \times \frac{d B}{d t}\right)}{d t}+\frac{d\left(\frac{\partial f}{\partial S} \times \frac{d S}{d t}\right)}{d t}
\end{gathered}
$$

As mentioned earlier, the implementation of the intervention is to create a turning point, namely making $\frac{d^{2} E}{d t^{2}}=0$ thus $\rightarrow$

$$
\left(\frac{\partial f}{\partial B}\right) d B=-\left(\frac{\partial f}{\partial S}\right) d S
$$

considering the intervention operation system's delaying natures, we can not compliment instantaneously, therefore in the $(\mathrm{t}-\mathrm{n})$ period of time, the result is:

$$
\int_{t}^{n} \frac{\partial f}{\partial B} \Delta B d t=-\int_{t}^{n} \frac{\partial f}{\partial S} \Delta S d t
$$

From the perspective of mathematics: Equation (1) and equation (2) reflects the concept of a speed, namely the increase (or decrease) speed of B must equal to the decrease (or increase) speed of $\mathrm{S}$, therefor forming a reversal tendency. However, the increase or decrease speed of an "Object" is determined by the "quality" of itself. In the foreign exchange market, the word "quality" can be understood as the amount of money from both sides_ — long position and short position.

The above principles have proved that : at the right price, on the proper time, the intervening money should suddenly enter the markets with sufficient size, which ought to be enough to penetrate "stop loss" points of "counter-parties" -all of these are important conditions to make inversion tides in FX markets. 
If the exchange rate curve $\mathrm{E}$ were to be turned to a reversal tendency, thus in a certain period of time forming a "sharp point" which conforms to the wills of Intervention Authority, meanwhile, $\operatorname{lnE}$ appeared to be a "new standard normal distribution", this kind of Intervention could be regarded as a successful one.

\subsection{Intervention Analysis on the External Conditions}

Due to "U.S. Dollar Pegging" mechanism, in the foreign exchange market, there exists a relevant pricing system accordingly, so for Non-American country's Monetary Authorities, it is essential to cooperate with Dollars Issuing Authority of the United States. Because once the country's currency intervention were to make local currency depreciate, the behavior could be hedged by the United States. If the U.S. regards some interventions as a kind of manipulation to currencies, he will implement anti-intervention, causing the global foreign exchange markets to hedge the intervening country's behavior, and no country can defend himself under such circumstances. Furthermore, many terminal platforms of the foreign exchange markets are almost in the United States, so to collaborate with the relevant "oligarchs" of market makers is very important -if coordinated intervention were to be realized, the relative country could get the twice results with half the effort. This is the external guarantee to Intervention, as well as one of the reasons why the relevant countries must hold the alliance with the United States.

\section{Conclusion}

As RMB's Internalization stepping into a new era, we must think about the Mechanism of Intervention. For China's RMB, after being converted internationally, to be virtually traded will experience a period of time (10-15 years). Besides many other problems arising from it, how to intervene the International FX markets is one of the most important issues. If we were not able to do it well, it might be better for us to keep current situation of RMB unchanged. So we should learn from advanced techniques and lessons of other developed countries, especially learning from Japanese experience, therefore making our own Financial Intervention Scheme change for the better.

\section{References}

John, C. Hull. (2009). Risk Management and Financial Institutions. Peking China Machine Press, (9).

McCarthy, Ed. (2012, July-August). Structural Inefficiency. CFA Magazine.

McDonald, \& Robert, L. (2006). Derivative Markets (2nd ed.). Addison-Wesley, Pearson Education.

Michael Lovelady. (2013, April). Visual Quantitative Finance: A New Look at Option Pricing, Risk Management, and Structured Securities. Pearson Education, Inc.

Paul R. Krugman, \& Maurice Obstfeld. (2002). International Economics theory and Policy (Fifth ed.). Addison-Wesley Publishing Company. 